\title{
Construção e Estudo Preliminar da Escala de Crenças Compartilhadas Sobre Psicólogos
}

\author{
Construction and Preliminary Study of the Scale of Shared Beliefs about Psychologists \\ Construcción y Estudio Preliminar de la Escala de Creencias Compartidas sobre Psicólogos
}

\section{Fernanda Carneiro dos Santos}

Graduanda em Psicologia pela Universidade Federal da Bahia.

\section{Marione Souza Campos}

Graduanda em Psicologia pela Universidade Federal da Bahia. Bolsista de Iniciação Científica PIBIC/CNPQ no grupo Indivíduo, Organização e Trabalho, Diretora de projetos na Empresa Júnior de Psicologia da UFBA - Psicojunior.

Conselheira da UNIJr-Ba - Federação das Empresas Juniores da Bahia.

\section{Yasmin do Vale Figueiredo}

Graduanda em Psicologia pela Universidade Federal da Bahia. Bolsista de Iniciação Científica PIBIC/CNPQ no grupo Indivíduo, Organização e Trabalho.

\section{Thatiana Helena de Lima}

Psicóloga, Mestre e Doutora em Psicologia, pela Universidade São Francisco. Professora Adjunta na Universidade Federal da Bahia. Coordenadora da Liga Acadêmica em Saúde do Trabalhador. Editora Assistente da Revista

Psicologia: Ensino \& Formação. E-mail: thatianahlima@gmail.com

\section{Resumo}

Este artigo tem por objetivo apresentar o processo de construção e busca de evidências de validade da Escala de Crenças Compartilhadas sobre os Psicólogos (ECCP). A construção do instrumento se deu a partir dos insumos de uma entrevista semiestruturada aplicada a 22 participantes. Optou-se por criar os itens da ECCP a partir da entrevista semiestruturada devido à grande escassez de estudos sobre crenças compartilhadas acerca dos psicólogos. Após a análise dos achados da entrevista semiestruturada, os itens foram elaborados e usados para a construção do questionário, cuja escala é do tipo Likert de cinco pontos. O questionário foi aplicado em 235 sujeitos. Após sua aplicação, foi realizada a análise fatorial exploratória (AFE). Os testes de Kaiser-Meyer-Olkin (KMO) e de esfericidade de Bartlett apontaram para a fatorabilidade da matriz. A análise apontou para a extração de sete fatores antes da rotação dos componentes, contrariando a expectativa do estudo, que propunha a existência de cinco fatores no total. Após fixar uma solução de cinco fatores, percebeu-se que a análise do agrupamento dos itens não se revelou satisfatoriamente interpretável.

Palavras-chave: crenças; crenças compartilhadas; crenças sobre os psicólogos

\section{Abstract}

This article aims to present the process of construction and searching for evidence of validity of the Scale of Shared Beliefs about Psychologists, or Escala de Crenças Compartilhadas sobre os Psicólogos (ECCP) in Portuguese. The construction of the instrument was based on the inputs of a semi-structured interview applied to 22 participants. The ECCP items were created from the semi-structured interview due to the noticeable shortage of studies on shared beliefs about psychologists. After analyzing the findings of the semi-structured interview, the items were elaborated and used to construct the questionnaire, with a five-point Likert scale. The questionnaire was submitted to 235 respondents. Thereafter, the exploratory factor analysis (AFE) was performed. The Kaiser-Meyer-Olkin test (KMO) and Bartlett's test for sphericity pointed the matrix factor. The analysis indicated the extraction of seven factors 
before the component rotation, contrary to the expectation of the study, which had proposed the existence of five factors in total. After establishing a solution of five factors, it was noticed that the analysis of the grouping of items did not prove itself satisfactorily interpretable.

Keywords: beliefs; shared beliefs; beliefs about psychologists.

\section{Resumen}

Este artículo tiene por objetivo presentar el proceso de construcción y búsqueda de evidencias de validez de la Escala de Creencias Compartidas sobre los Psicólogos (ECCP). Se construyó el instrumento a partir de los insumos de una entrevista semiestructurada aplicada a 22 participantes. Se optó por crear los ítems de la ECCP a partir de la entrevista semiestructurada debido a la gran escasez de estudios sobre creencias compartidas acerca de los psicólogos. Después del análisis de los resultados de la entrevista semiestructurada, los ítems fueron elaborados y usados para la construcción del cuestionario, cuya escala es del tipo Likert de cinco puntos. El cuestionario se aplicó a 235 sujetos. Después de su aplicación, se realizó el análisis factorial exploratorio (AFE). El test de Kaiser-Meyer-Olkin (KMO) y la prueba de esfericidad de Bartlett apuntaron a la factorabilidad de la matriz. El análisis indicó la extracción de siete factores antes de la rotación de los componentes, contrariando la expectativa del estudio, que proponía la existencia de cinco factores en el total. Tras fijar una solución de cinco factores, se percibió que el análisis del agrupamiento de los ítems no se reveló satisfactoriamente interpretable.

Palabras-clave: creencias; creencias compartidas; creencias sobre los psicólogos.

Desde o ano de sua regulamentação como ciência e profissão no Brasil, em 1962, a Psicologia promoveu contribuições significativas em diferentes setores da sociedade, tendo como atuação principal a psicoterapia ou psicologia clínica. As contribuições e intervenções profissionais serviram de base para a formação de diversas crenças compartilhadas pelas pessoas a respeito dos profissionais atuantes nesta área.

A partir da busca na literatura sobre o tema “crenças", percebeu-se que este construto é bastante investigado e discutido por diversos teóricos; no entanto, élamentável que o mesmo não possa estar relacionado às crenças compartilhadas sobre os psicólogos. Isso posto, tem-se que as crenças concernentes aos profissionais de Psicologia configuram-se como tema ainda pouco abordado pelos teóricos brasileiros, havendo, portanto, grande carência bibliográfica em relação aos estudos que podem vir a tangenciá-lo. Por conseguinte, percebe-se a oportunidade, ampla e necessária, de investigar este construto, com maior grau de aprofundamento científico.

À vista disso, o presente trabalho tem por objetivo apresentar a construção e os estudos psicométricos de uma escala a respeito das crenças compartilhadas pela população brasileira sobre os profissionais de psicologia. Foram utilizados como referenciais teóricos acerca do tema os estudos de Kruger e Bem, autores de grande relevância para se entender o sistema de crenças e como elas estão fundamentadas.

Desse modo, o estudo se mostra relevante por apresentar um instrumento que futuramente subsidiará a compreensão sobre as crenças compartilhadas pela população brasileira em relação aos profissionais de Psicologia; e seus resultados possibilitarão a obtenção de recursos empíricos para se pensar sobre a intervenção sistemática por parte dos psicólogos sobre sua atuação. Presume-se que entender quais as crenças compartilhadas pela população em relação ao psicólogo implicará a criação de ações para demarcação da atuação por parte desses profissionais, bem como dos estudantes dessa área.

O profissional da Psicologia, bem como sua atuação enquanto psicólogo, vem sendo percebido e compreendido pela sociedade de forma variada, principalmente devido a influências do período histórico corrente e precedente, classe social pertencente, nível de contato com o profissional, 
mídia atuante, entre outros fatores. Em outras palavras, a depender de quem os vê e de quando os vê, o psicólogo e sua atuação podem ser compreendidos de diferentes formas. Isso posto, identificar as crenças compartilhadas de dada população sobre os psicólogos requer compreender, ainda que sumariamente, o percurso histórico de tal profissão e suas repercussões no pensamento contemporâneo.

Nesse sentido, far-se-ão a seguir uma breve revisitação histórica da Psicologia enquanto ciência e profissão, e uma sucinta revisão do que tem sido discutido na literatura sobre características da profissão ou do profissional bem como os dados ou crenças até então trabalhados. Em seguida, será apresentado de forma mais aprofundada o conceito de crença, e discutida sua relevância para a compreensão e possível predição das condutas humanas.

A história da profissionalização da Psicologia no Brasil pode ser dividida em três momentos distintos: o pré-profissional (1833-1890), a profissionalização (1890/1906-1975), e o profissional (1975) (Pereira \& Pereira Neto, 2003). O primeiro período se caracteriza pelo surgimento do interesse a respeito de temas ligados a questões psicológicas. Entretanto, tal processo ocorreu de forma incipiente, não institucionalizada.

O segundo período se caracteriza pela institucionalização da prática e regulamentação da Psicologia como profissão; os pontos marcantes desse período são a criação do Laboratório de Psicologia Experimental por Wilhelm Wundt, em 1879 na Alemanha e a elaboração do código de ética em 1975. A criação do laboratório significou a ruptura das ideias psicológicas como abstratas e espiritualistas, o que fortaleceu o vínculo da Psicologia com princípios e métodos científicos (Bock, Furtado, \& Teixeira, 1999). Em 27 de agosto de 1962, a Psicologia é regulamentada como profissão pela Lei $n^{\circ} 4.119$, e as suas funções foram especificadas no Decreto $n^{0} 53.464$, que possibilitou ao psicólogo atuar em diferentes campos, como na área escolar, do trabalho, clínica, acadêmica ou jurídica. Em 1971, foram então criados o Conselho Federal e os Conselhos Regionais de Psicologia.
O terceiro período, a partir de 1975, é marcado pelo início da consolidação da Psicologia enquanto profissão: surgiram novos cursos universitários, novos profissionais, e uma crescente demanda pelos serviços psicológicos. Nesse sentido, a Psicologia passa a fazer parte do cotidiano da população por meio de manuais de comportamento, revistas, programas de TV e livros sobre sexualidade (Pereira \& Pereira Neto, 2003). Segundo Pereira e Pereira Neto (2003), deitar no divã no referido período era considerado sinal de status social, havendo enorme demanda nos consultórios psicológicos por parte das classes média e alta da população. O predomínio da atuação dos profissionais nesse ambiente refletia o interesse pela área clínica e o ideal do atendimento feito em consultório.

Outra característica encontrada na literatura a respeito dos psicólogos após a regulamentação da Psicologia como profissão é o predomínio do sexo feminino entre os profissionais (Castro \& Yamamoto, 1998). Segundo pesquisa realizada pelo Conselho Federal de Psicologia em 2012, a composição do quadro de profissionais de Psicologia caracterizava-se pelo predomínio de mulheres (com percentuais de $89 \%$ de mulheres), adultas (57\% dos profissionais estavam na faixa de 30 a 49 anos), e de cor branca (67\% das mulheres se declararam "brancas") (Conselho Federal de Psicologia - CFP, 2013).

Com o processo da consolidação da Psicologia como profissão, a figura do psicólogo passou a fazer parte da cultura nacional, o que levou a população a criar e compartilhar crenças a respeito deste profissional. Segundo Daryl Bem (1973), as crenças são conteúdos simbólicos que dizem sobre a relação entre objetos concretos e/ou abstratos, ou entre estes e uma ou mais de suas características. Ou seja, "se um homem percebe alguma relação entre duas coisas, ou entre alguma coisa e uma das suas características, diz-se que ele tem uma crença" (Bem, 1973, p.12).

De forma complementar, para Helmuth R. Krüger (1995) crença é um termo de uso consolidado, e sua definição possui significativa importância instrumental, especialmente para a Psicologia Social. Conforme o autor, as crenças 
podem ser compreendidas como afirmações feitas por uma pessoa com base nas suas experiências pessoais. Os conteúdos abstratos manifestamse objetivamente mediante a linguagem oral e escrita, e associam-se com "os processos cognitivos, afetivos, motivacionais e cognitivos de modo geral" (Krüger, 1995, p. 383). Assim, como bem destaca Krüger, crença é um construto de natureza latente que pode ser investigado e medido indiretamente a partir da análise dos comportamentos orais/escritos que o exprimem.

Krüger (1995) assevera que, no processo de construção do eu, as pessoas desde a infância desenvolvem crenças sobre si mesmas, sobre outras pessoas, sobre as instituições, as entidades abstratas, as situações, etc. Cada sujeito vai aderindo, ao longo da vida, a um número substancial de crenças que se associam umas às outras, seja de forma contraditória ou complementar, configurando-se como um sistema norteador da relação indivíduo-sociedade.

Em consonância com isso, Bem (1972) especifica que as crenças e as atitudes humanas se fundamentam em quatro atividades: o pensar, o sentir, o comportar-se e o interagir. Dessa forma, os fundamentos psicológicos das crenças e das atitudes seriam divididos em cognitivos (pensar), emocionais (sentir), comportamentais e sociais (interagir com os outros). Os fundamentos sociais, por exemplo, mostram que a influência de pais, amigos, professores, colegas, entre outros, no sistema de crenças pode ser superficial ou profunda. O meio social pode influenciar na construção das crenças ou no enraizamento destas de diversas maneiras, seja pelos meios de comunicação de massa, pelas influências interpessoais e normas sociais, ou por meio dos grupos de referências e influências oriundas das gerações e hierarquias. Assim, é possível perceber que as crenças sobre o profissional de Psicologia, por exemplo, vêm sendo elaboradas e difundidas desde que foi inaugurada ciência, ou até mesmo antes já havia escritos de filósofos que tratavam do tema, tentando compreender os processos psicológicos.

De acordo com Weber (2005), a concepção social a respeito da Psicologia está demasiadamente vinculada à psicoterapia. O autor apoia este argumento com um estudo realizado pelo Conselho Federal de Psicologia em que a clínica se destaca como área de atuação preferida pelos psicólogos, com um índice de 54,9\%, conforme apontam dados. A população, tendo maior contato com profissionais nesta área em particular, pode acabar desenvolvendo crenças a respeito desta categoria social (psicólogos) que, baseadas em suas experiências pessoais cujo conteúdo gira em torno de uma atuação restrita à clínica e/ou à área da saúde. Desse modo, as crenças elaboradas apresentam, de certa forma, uma redução da atividade profissional do psicólogo, excluindo um leque de possibilidades para o ato de ser psicólogo.

Diante o exposto até então, é possível apontar ainda que o estudo das crenças é de extrema importância para a compreensão e possível predição das condutas humanas, uma vez que estas se constituem, juntamente com os demais processos cognitivos, como vetor de influência dos comportamentos. Pode-se dizer que as crenças são multi-influenciadas e mediam as relações sociais, permitindo ao indivíduo que interprete suas experiências, ao mesmo tempo que orientam a sua conduta, visando ao seu ajuste pessoal (Krüger, 1995).

Desse modo, elaborar um instrumento capaz de medir e de possibilitar a compreensão das crenças sobre determinada categoria social - os psicólogos -, apresenta-se como de suma relevância para a predição de possíveis comportamentos da sociedade frente aos psicólogos. Além disso, compreender as crenças sobre os psicólogos possibilitará a esta categoria social insumos não só para refletir sobre possíveis mudanças e aprimoramento em sua atuação para melhor atender a expectativas e necessidades de seu público alvo, como também para apontar à sociedade crenças irracionais a respeito dessa categoria profissional, de modo a conscientizar a população sobre quem é o psicólogo e qual o objetivo de seu trabalho. Assim, o presente trabalho objetiva construir um instrumento de medida de crenças compartilhadas sobre psicólogos, bem como buscar evidências de validade para o mesmo. 


\section{Método}

\section{Participantes}

\section{Primeira etapa do estudo}

$\mathrm{Na}$ primeira etapa deste estudo, havia 22 participantes, de Salvador e da região metropolitana, com idade média de 39 anos, variando de 18 a 66 anos. A maioria era do sexo feminino (59\%), e o grau de escolaridade predominante na amostra era o ensino médio completo.

\section{Segunda etapa do estudo}

Participaram 235 sujeitos, com idades variando entre 18 e 67 anos, com média de 30 anos. Houve predominância do sexo feminino (64\%). Quanto à escolaridade, $37 \%$ - ou seja, a maior parte -, cursa o ensino superior; e a maioria dos participantes vivia na região Nordeste (89\%).

É importante informar que ambas as amostras foram obtidas por conveniência.

\section{Instrumento}

\section{Primeira etapa do estudo}

Fez-se uso de um roteiro para a entrevista semiestruturada. Este roteiro é composto por um pequeno questionário inicial, para identificação dos participantes, e por cinco perguntas abertas (o que você acha que o psicólogo faz; onde você acha que o psicólogo atua/trabalha; qual a importância do psicólogo para a sociedade e o grau de eficácia de sua atuação; qual imagem [traços físicos, psicológicos e comportamentais] você tem de um psicólogo; e você tem ou já teve contato com psicólogos ou estudantes de Psicologia) com o intuito de subsidiar o desenvolvimento da entrevista. Este primeiro instrumento teve como objetivo identificar a percepção que os indivíduos têm acerca do profissional psicólogo, sua atuação, seus campos de intervenção e a importância e eficiência de seus serviços para a sociedade, servindo como base para a elaboração das dimensões e dos itens do instrumento.
Segunda etapa do estudo

Com a primeira coleta de dados finalizada e, por conseguinte, a análise de seus achados trabalhada, foi possível construir uma escala quantitativa com intuito de medir o construto "crenças compartilhadas sobre os psicólogos”. Após a elaboração dos itens, percebeu-se que estes se agrupavam exclusivamente em cinco dimensões: "quem é o psicólogo, diz respeito às possíveis crenças sobre características físicas, psíquicas e comportamentais atribuídas ao profissional de psicologia; "o que o psicólogo faz", às crenças a respeito das atividades e habilidades próprias do profissional de Psicologia para o exercício de sua respectiva profissão; “onde o psicólogo atua”, às crenças concernentes a possíveis áreas em que o profissional de Psicologia atua; "por que as pessoas procuram o psicólogo”, às crenças a respeito dos motivos que levam as pessoas a procurarem o psicólogo; "qual a importância do trabalho do psicólogo", às crenças a respeito da importância dada para atuação profissional do psicólogo. Com isso, foram criados itens para cada uma das cinco dimensões propostas.

Por fim, na segunda etapa da pesquisa, o instrumento utilizado foi composto por um questionário inicial, para a coleta dos dados sociodemográficos dos participantes, e da escala, com 20 itens de tipo Likert, com cinco pontos para as respostas, em que um representa "discordo totalmente" e cinco "concordo totalmente".

\section{Procedimentos de coleta de dados}

\section{Primeira etapa do estudo}

Fez-se uso do Termo de Consentimento Livre e Esclarecido (TCLE), entregue ao participante, seguido da entrevista semiestruturada, conforme consentimento do participante e assinatura do termo. A aplicação foi realizada de forma presencial e individualmente, em aproximadamente 15 minutos. 
Segunda etapa do estudo

Foi realizado contato com os participantes da pesquisa, e a escala foi enviada em formato de questionário online por meio das redes sociais, via internet, acompanhada do TCLE. Estima-se que foram respondidas em aproximadamente 15 minutos.

\section{Procedimentos de análise de dados}

Primeira etapa do estudo

Os dados provenientes da entrevista semiestruturada foram tratados a partir de uma análise de conteúdo (Bardin, 2009), sendo, por conseguinte, categorizados e usados como subsídio para a construção do questionário quantitativo.

\section{Segunda etapa do estudo}

A escala do tipo Likert de cinco pontos, composta por 20 itens, foi submetida à AFE. Utilizou-se o programa estatístico SPSS versão 22. Foram utilizados os índices KMO, Teste de Esfericidade de Bartlett, Critério de KaiserGuttman (eigenvalue>1), Teste de ScreePlot e rotação promax com neutralização de Kaiser.

\section{Resultados}

Resultados da primeira etapa do estudo: entrevista semiestruturada

Mediante as respostas obtidas nessa etapa do estudo, foi possível realizar a análise de conteúdo que, partindo dos discursos mais frequentes dos entrevistados, permitiu a identificação de cinco categorias referentes às crenças das pessoas sobre o psicólogo: o que o psicólogo faz, onde o psicólogo atua, qual a importância do psicólogo, quem é o psicólogo e por que as pessoas procuram os psicólogos. Partindo dos discursos mais recorrentes em cada categoria, foi pensada a estruturação dos itens da escala psicométrica.

\section{Resultados da segunda etapa do estudo: Escala de Crenças Compartilhadas sobre psicólogos}

Inicialmente verificou-se a fatorabilidade da matriz de correlações dos 20 itens da escala ECCP, a qual se apresentou adequada: $\mathrm{KMO}=0,72$ e o Teste de Esfericidade de Bartlett $=\chi^{2}(190)=694,900$, $p<0,001$. Como o objetivo foi identificar possíveis construtos teóricos latentes, foi realizada AFE, adotando o método de extração dos eixos principais (PAF) e rotação promax (Fabrigar, Wegener, MacCallum \& Strahan, 1999). Para verificar o número de fatores a serem retidos, utilizou-se o critério de eigenvalue maior do que 1,00 e o teste scree (Laros, 2004).
Os resultados da AFE indicaram a existência de sete fatores com eigenvalues maiores que 1,0. 0 teste scree, que pode ser visualizado na Figura 1 , suporta esta solução, com uma substancial quebra no gráfico após o sétimo fator. Esses resultados indicam a extração de sete fatores, que explicaram 57,5\% da variância total.

Analisando os dados segundo a retenção de fatores, nota-se que os resultados do teste ScreePlot e da análise da matriz de componentes mostraram-se semelhantes, produzindo uma estrutura de sete fatores cada. $O$ primeiro fator agrupa os itens $1,2,4,5,8,9,11,12$ e 14 . O segundo fator agrupa os itens 7, 13, 17, 18 e 20 . O terceiro fator agrupa o item 3. O quarto fator agrupa os itens 10, 15 e 19. O quinto fator agrupa o item 6. O sexto fator (não agrupa qualquer item). O sétimo fator agrupa o item 16 .

Visando solucionar os problemas apresentados pela matriz de componentes com sete fatores (como os exemplos do sexto fator e da concentração de cargas em poucos fatores), mostrou-se viável e necessário fixar um número de cinco fatores para análise dos resultados, de forma a enquadrar também os resultados ao proposto inicialmente pelo presente estudo.

Ao serem fixados os cinco fatores (variância explicada total $=47,2 \%$ ), percebeu-se que a única mudança relacionada às cargas fatoriais dos itens 


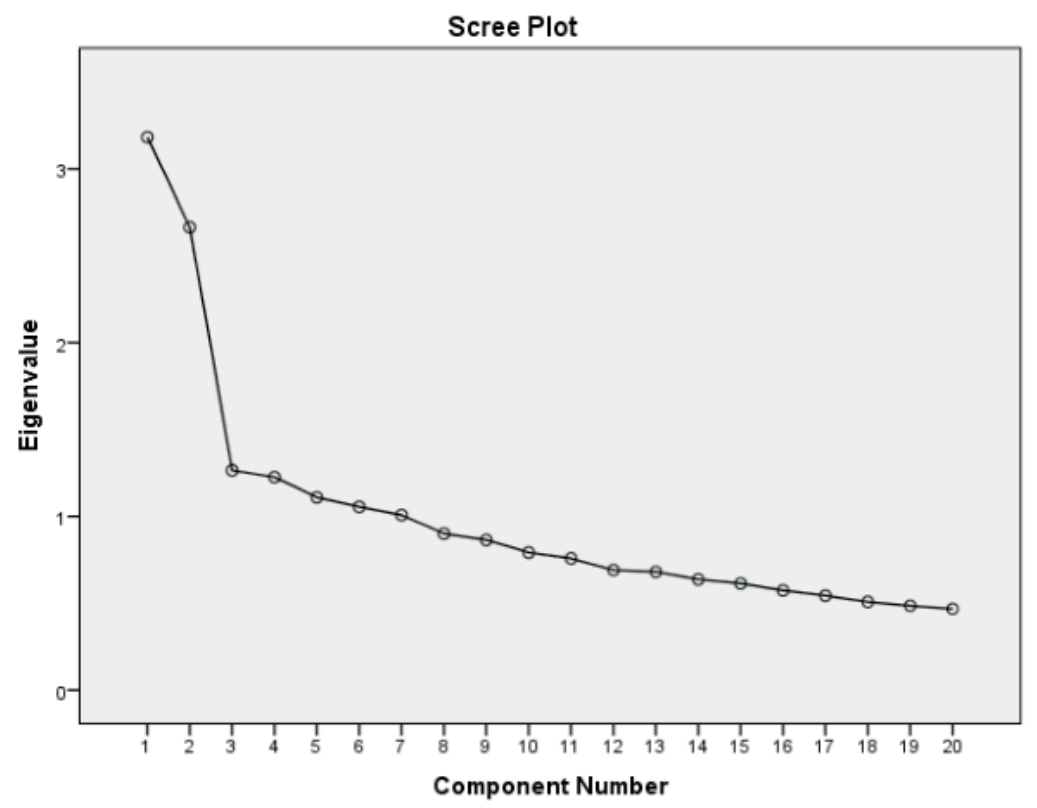

Figura 1 - ScreePlot para a verificação do número de fatores

sobre os fatores aconteceu no item 16 , que deixou de pertencer ao fator 7 (da matriz de componentes com sete fatores) para ser abarcado pelo fator 1 , com carga igual a 0,366, como mostra a Tabela 1.

Percebe-se, no entanto, que a solução de cinco fatores, prevista inicialmente na construção do instrumento, também não foi adequada, visto que nos fatores 5 e 7 há apenas um item para cada um desses fatores. Ainda, algumas cargas fatoriais foram negativas, o que também merece mais estudo. Assim, outras estruturas fatoriais do instrumento devem ser realizadas.

\section{Tabela 1}

Matriz de componentes de cinco fatores

\begin{tabular}{|c|c|c|c|c|c|}
\hline Item & Fator 1 & Fator 2 & Fator 3 & Fator 4 & Fator 5 \\
\hline $\begin{array}{l}\text { 1. Em minha opinião, o trabalho do psicólogo é escutar } \\
\text { as pessoas. }\end{array}$ & 0,471 & & & & \\
\hline 2. Eu acho que os psicólogos devem ser calmos. & 0,489 & & & & \\
\hline 3. Eu acho que os psicólogos são sensíveis. & & & 0,619 & & \\
\hline $\begin{array}{l}\text { 4. Eu acho que os psicólogos têm relacionamentos } \\
\text { afetivos mais saudáveis que as pessoas em geral. }\end{array}$ & 0,480 & & & & \\
\hline $\begin{array}{l}\text { 5. Acredito que as mulheres são mais sensíveis para } \\
\text { exercer a Psicologia. }\end{array}$ & 0,624 & & & & \\
\hline $\begin{array}{l}\text { 6. Eu acho que, durante o atendimento, os psicólogos são } \\
\text { desatentos à fala dos clientes. }\end{array}$ & & & & & 0,502 \\
\hline $\begin{array}{l}\text { 7. Eu acho que o diagnóstico do psicólogo é importante } \\
\text { no auxílio de tomada de decisões em processos } \\
\text { jurídicos. }\end{array}$ & & 0,563 & & & \\
\hline $\begin{array}{l}\text { 8. Em minha opinião, o psicólogo compreende o cliente } \\
\text { melhor que o próprio cliente compreende a si mesmo. }\end{array}$ & 0,491 & & & & \\
\hline $\begin{array}{l}\text { 9. Em minha opinião, os psicólogos podem medicar seus } \\
\text { pacientes. }\end{array}$ & 0,496 & & & & \\
\hline
\end{tabular}


Tabela 1 (continuação)

Matriz de componentes de cinco fatores

\begin{tabular}{|c|c|c|c|c|c|}
\hline Item & Fator 1 & Fator 2 & Fator 3 & Fator 4 & Fator 5 \\
\hline $\begin{array}{l}\text { 10. Eu acho desnecessária a presença do psicólogo na } \\
\text { área esportiva. }\end{array}$ & & & & $-0,490$ & \\
\hline $\begin{array}{l}\text { 11. Eu acredito que os testes psicológicos servem para } \\
\text { comprovar suspeitas relacionadas a problemas } \\
\text { psíquicos. }\end{array}$ & 0,458 & & & & \\
\hline $\begin{array}{l}\text { 12. Eu acho que a clínica é o lugar onde o psicólogo } \\
\text { trabalha. }\end{array}$ & 0,575 & & & & \\
\hline $\begin{array}{l}\text { 13. Eu acho que audiências jurídicas são áreas de atuação } \\
\text { nas quais o psicólogo tem capacidade de atuar. }\end{array}$ & & 0,574 & & & \\
\hline $\begin{array}{l}\text { 14. Eu acho que as pessoas procuram a ajuda do } \\
\text { psicólogo quando surtam. }\end{array}$ & 0,431 & & & & \\
\hline $\begin{array}{l}\text { 15. Na minha concepção, os psicólogos são } \\
\text { desnecessários em acompanhamentos de pacientes } \\
\text { em tratamentos médico- hospitalares. }\end{array}$ & & & & $-0,491$ & \\
\hline $\begin{array}{l}\text { 16. Eu acho que a seleção para vagas de emprego não } \\
\text { precisa ser feita por um psicólogo. }\end{array}$ & 0,366 & & & & \\
\hline $\begin{array}{l}\text { 17. Eu acho que uma conversa entre amigos tem o } \\
\text { mesmo efeito que uma conversa em um ambiente } \\
\text { terapêutico. }\end{array}$ & & $-0,579$ & & & \\
\hline $\begin{array}{l}\text { 18. Em minha opinião, os psicólogos são tão } \\
\text { importantes quanto os médicos e nutricionistas para } \\
\text { a saúde das pessoas. }\end{array}$ & & 0,605 & & & \\
\hline $\begin{array}{l}\text { 19. Eu acho que, se a pessoa já é atendida por um } \\
\text { psiquiatra, não precisa ser atendida por um psicólogo. }\end{array}$ & & & & 0,628 & \\
\hline $\begin{array}{l}\text { 20. Eu acho que o dinheiro investido em um } \\
\text { acompanhamento psicológico pode ser mais bem } \\
\text { empregado em outras finalidades. }\end{array}$ & & $-0,533$ & & & \\
\hline
\end{tabular}

\section{Discussão}

À luz dos resultados expostos na seção anterior, foi possível identificar que o critério de Kaiser-Guttman (eigenvalue $>1$ ) e o Teste do ScreePlot revelaram a distribuição dos itens em sete fatores com eigenvalue acima de 1,00. Desse modo, fez-se uma análise aprofundada para verificar a possibilidade de o construto "crenças compartilhadas sobre os psicólogos" ser multidimensional, constituído por sete fatores. Percebeu-se, no entanto, que apenas o item 16 carregou no sétimo fator, e os itens 17 e 20 carregaram simultaneamente no segundo e sexto fatores, tendo carga fatorial maior no segundo fator. Assim sendo, fica clara a inviabilidade de continuar com a configuração de sete fatores para o construto, uma vez que o sexto e o sétimo apresentaram uma variância explicada muito baixa, quando comparados aos demais.

A partir dessa constatação e ainda do fato de essa matriz de sete fatores apresentar uma tendência a superestimar o número de fatores, foi fixado no programa a solução fatorial em cinco fatores, conforme previsto pelos insumos da primeira etapa do estudo, previamente apresentada. A estrutura de cinco fatores mostrouse viável em termos de variância explicada; no 
entanto, a análise da distribuição dos itens por esses fatores não se revelou satisfatoriamente interpretável. Em alguns fatores, apenas um item foi carregado; isso confirma que o instrumento não está apropriado, sabendo que os itens são agrupados pelas respostas dos sujeitos, e que este item foi respondido de forma diferente dos demais itens pelos sujeitos. Algumas cargas fatoriais foram negativas; porém, ao analisar o conteúdo do item faz sentido, por exemplo o item "eu acho que uma conversa entre amigos tem o mesmo efeito que uma conversa num ambiente terapêutico" relaciona-se negativamente com os demais itens do fator, como por exemplo o item "eu acho que o diagnóstico do psicólogo é importante no auxílio de tomada de decisões em processos jurídicos".

Embora o estudo qualitativo tenha apontado para a existência de cinco dimensões, como apresentadas anteriormente, a solução fatorial de cinco fatores do SPSS não corroborou com a distribuição dos itens nas dimensões da forma como pensada previamente. Os itens se agruparam de forma diferente à proposta pela primeira etapa do estudo, revelando-se como um impasse quanto à estrutura fatorial do construto em questão.

Nesse sentido, é importante buscar a melhor solução fatorial para o presente instrumento. Tem-se até então que a solução de sete fatores já se mostrou inviável, assim como a solução de cinco fatores não se mostrou satisfatoriamente interpretável. Observando a figura do SreePlot, percebe-se que os dois primeiros fatores possuem a maior variância explicada; neste caso, é necessário buscar uma estrutura fatorial que esteja adequada para a escala.

É importante pontuar duas possíveis hipóteses sugeridas para a explicação da presente incongruência no agrupamento dos itens sugerido pela fatoração. A primeira diz respeito à escassez de estudos sobre as crenças compartilhadas acerca dos psicólogos, o que resultou na elaboração da ECCP proveniente dos insumos de um instrumento qualitativo, em vez de uma teoria previamente estabelecida acerca do construto. Sugere-se, nesse sentido, que a elaboração da escala partindo dos insumos de um instrumento qualitativo, em vez de uma teoria, teria influenciado e talvez enviesado a construção dos itens do instrumento. Já a segunda hipótese sugere a possibilidade de o construto ser unifatorial. Assim, seria necessária outra análise fatorial para explorar melhor tal possibilidade.

A respeito da primeira hipótese, a saber, a elaboração do instrumento tendo por base uma teoria, acredita-se que essa também foi uma limitação do presente estudo. A pesquisa poderia ter partido da base teórica de representações sociais acerca dos psicólogos e da atuação dos mesmos. Alguns estudos podem ser encontrados nessa área, como os de Leme, Bussab, e Otta (1989); Praça e Novaes (2004); Borsezi, Bortolomasi, Liboni, Reis, Tamanaha, e Guimarães (2008); Oliveira e Peres (2009); e Assis e Matthes (2014).

Vale ressaltar que este trabalho teve por objetivo apenas explorar os dados obtidos, e que a busca por evidências de validade e precisão são importantes para que se possa constatar uma medida mais precisa. Dito isso, outros estudos devem-se debruçar sobre o construto, e principalmente sobre suas possibilidades ou não de fatoração.

De forma geral, é possível afirmar que a ECCP é importante visto a escassez de instrumentos que avaliem o construto proposto, e que outros estudos devem ser realizados com o intuito de fornecer evidências de validade para a escala e, se necessário, de reformular os itens para que representem melhor o construto. Entretanto, algumas limitações deste instrumento devem ser ressaltadas a fim de mapear os aprimoramentos necessários para futuros estudos. Deste modo, a começar pelos possíveis vieses amostrais na primeira e segunda etapa do estudo, tem-se que na primeira etapa $82 \%$ dos participantes eram moradores de Salvador-Bahia, e na segunda etapa cerca de $89 \%$ dos participantes eram da região Nordeste. Outro fator que pode ter limitado os resultados da pesquisa foi o pequeno número de entrevistas realizadas na primeira etapa da construção do instrumento, assim como a falta de elementos da literatura para a elaboração dos itens. A análise das respostas obtidas pelas entrevistas poderia ter sido ampliada, por conta dessa falta de dados bibliográficos, de modo a utilizar também as indicações menos recorrentes 
a fim de expandir o número de itens da escala.

Sugere-se que novos estudos sejam realizados nessa área, utilizando amostras que sejam realmente representativas da sociedade brasileira como um todo, e com um maior número de expertises na análise semântica. De todo modo, recomenda-se o uso desta escala como fonte de dados para futuras pesquisas que visem a um maior aprimoramento dos dados psicométricos, e por conseguinte busquem avançar na compreensão das crenças da sociedade sobre os profissionais de Psicologia. Este estudo se faz importante para a formação dos psicólogos. Segundo Yamamoto, Trindade, e Oliveira (2002), o perfil do psicólogo pode ser constituído mediante a comunicação de pessoas que já fizeram a utilização do serviço de Psicologia e demonstraram sua satisfação ou insatisfação para as pessoas mais próximas. A postura do profissional, que pode ser incoerente às vezes por ter tido uma formação deficiente e limitada, pode contribuir para a criação de crenças errôneas do que é a Psicologia, assim como daquele que exerce a profissão.

\section{Referências}

Assis, C. L., \& Matthes, G. A. S. (2014). Representações sociais sobre a psicologia e o psicólogo em universitários de uma faculdade privada de Rondônia, Brasil. Aletheia, 43-44, 66-90. Recuperado de http://pepsic. bvsalud.org/scielo.php?script=sci_arttext\&pid =S1413-03942014000100006

Bardin, L. (2009). Análise de Conteúdo. Lisboa: Edições 70.

Bem, D. J. (1973). Convicções, atitudes e assuntos humanos. São Paulo: EPU.

Bock, A. M. B., Furtado, O., \& Teixeira, M. L. T. (1999). Psicologias. São Paulo: Saraiva.

Borsezi, C. S., Bortolomasi, E., Liboni, R. G., Reis, M. F., Tamanaha, H. Y., \& Guimarães, J. L. (2008). Representação social da psicologia e do psicólogo sob o olhar da comunidade de Assis/SP - Brasil. Psicologia para América Latina, 14. Recuperado de http://pepsic. bvsalud.org/scielo.php?script=sci_arttext\&pid=S1870350X2008000300010\&lng=pt\&tlng=pt

Castro, A. E. F., \& Yamamoto, O. H. (1998). A Psicologia como profissão feminina: apontamentos para estudo. Estudos de psicologia (Natal), 3(1), 147-158. doi: 10.1590/ S1413-294X1998000100011

Conselho Federal de Psicologia. (2013). Quem são as psicólogas brasileiras? Disponível em http://site.cfp. org.br/wp-content/uploads/2013/03/Uma-profissaode-muitas-e-diferentes-mulheres-resultado-preliminarda-pesquisa-2012.pdf

Fabrigar, L. R., Wegener, D. T., MacCallum, R. C., \& Strahan, E. J. (1999). Evaluating the use of exploratory factor analysis in psychological research. Psychological Methods, 4(3), 272-299. doi: 10.1037/1082-989X.4.3.272

Gebara, C. F. P., \& Lourenço, L. M. (2008). Crenças de profissionais da saúde sobre violência doméstica contra crianças e adolescentes. Psicologia em Pesquisa, 2(1), 27-39.

Krüger, H. (1995). Psicologia das crenças: perspectivas teóricas.
(Tese de Concurso para Professor Titular). Rio de Janeiro: Universidade do Estado do Rio de Janeiro - Instituto de Psicologia - Departamento de Psicologia Social e Institucional.

Laros, J. A. (2004). O uso da análise fatorial: algumas diretrizes para pesquisadores. In L. Pasquali (Org.), Análise fatorial para pesquisadores (pp. 147-170). Petrópolis: Vozes.

Leme, M. A. V. S., Bussab, V. S. R., \& Otta, E. (1989). A representação social da Psicologia e do psicólogo. Psicologia: Ciência e Profissão, 9(1), 29-35. doi: 10.1590/ S1414-98931989000100009

Maciel, S. C., Pereira, C. R., Lima, T. J. S., \& Souza, L. E. C. (2015). Desenvolvimento e validação da escala de crenças sobre a doença mental. Psicologia: Reflexão e Crítica, 28(3), 463-473. doi: 10.1590/1678-7153.201528305

Oliveira, M., \& Peres, K. N. (2009). A representação social de usuários e profissionais sobre a atuação do psicólogo nos serviços de saúde pública do município de Palmas/ TO. Revista Eletrônica de Psicologia e Políticas Públicas, 1(1), 35-57.

Pereira, F. M., \& Pereira Neto, A. (2003). O psicólogo no Brasil: Notas sobre seu processo de profissionalização. Psicologia em Estudo, 8(2), 19-27. doi: 10.1590/S141373722003000200003

Praça, K. B. D., \& Novaes, H. G. V. (2004). A representação social do trabalho do psicólogo. Psicologia: Ciência e Profissão, 24(2), 32-47.

Sanini, C., \& Bosa, C. A. (2015). Autismo e inclusão na educação infantil: Crenças e autoeficácia da educadora. Estudos de Psicologia (Natal), 20(3), 173-183. doi: 10.5935/1678-4669.20150019

Weber, L. N. D., Pavei, C. A., \& Biscaia, P. (2005). Imagem social do psicólogo e da psicologia para a população de Curitiba: 12 anos depois. Psicologia Argumento, 23(40), 19-30. Recuperado de https://goo.gl/hsRDte 